\title{
As memórias de Jorge Amado: O menino grapiúna e Navegação de cabotagem
}

\author{
The memories of Jorge Amado: \\ O menino grapiúna and Navegação de cabotagem \\ Maria Cleunice Fantinati SILVA* \\ Instituto Federal de Mato Grosso (IFMT) \\ Sheila Dias MACIEL ${ }^{* *}$ \\ Universidade Federal de Mato Grosso (UFMT)
}

\begin{abstract}
RESUMO: Reflexão sobre a escrita de memórias na trajetória literária de Jorge Amado, com o intuito de tecer relações entre as duas obras memorialistas por ele produzidas: O menino grapiúna (1981) e Navegação de cabotagem (1992). Para tanto, utiliza-se como aparato teórico o conceito de memórias apresentado por Olmi (2006) e Halbwachs (2006), além da divisão, proposta por Bosi (1989), sobre o conjunto da obra amadiana. Como resultado, apesar da diferença temporal que as separa, as duas memórias de Jorge Amado podem ser compreendidas como complementares, já que a correnteza da memória não necessariamente se esgota em uma única obra ou experiência narrativa autopromocional.
\end{abstract}

PALAVRAS-CHAVE: Literatura Brasileira. Jorge Amado. Memórias.

RESUMEN: Reflexiones sobre la escritura de las memorias en la trajectoria literaria de Jorge Amado, con el fin de señalar las relaciones entre las dos obras: O menino grapiúna (1981) y Navegação de cabotagem (1992). Para ello, se utiliza el concepto de las memorias presentadas por Olmi (2006) y Halbwachs (2006), y la división, propuesta por Bosi (1989), en toda la obra amadiana. Como resultado, a pesar de la diferencia de tiempo que separa las dos memorias de Jorge Amado se puede entenderlas como complementarias, ya que la corriente de la memoria no necesariamente se agota en una sola obra o experiencia narrativa de autopromoción.

PALABRAS CLAVE: Literatura Brasileña. Amado. Recuerdos.

\section{Introdução}

Alguns escritores brasileiros, tais como Visconde de Taunay, Oswald de Andrade e Érico Veríssimo, publicaram, como remate de uma trajetória literária de sucesso, textos de memórias.

As memórias, aceitas como forma narrativa em que um narrador autodiegético retoma o passado por meio do momento presente, costumam apresentar como marca distintiva um caráter autopromocional, ou seja, uma espécie de propaganda disfarçada de si que ocorre por se tratar de uma versão construída a partir do presente e de suas necessidades.

\footnotetext{
* Mestre em Estudos de Linguagem pela UFMT (2012). Professora do Instituto Federal de Estado de Mato Grosso ( IFMT), campus de Pontes e Lacerda. E-mail: cleunfansilva@ hotmail.com.

** Doutora em Letras, Professora Associada do Departamento de Letras do Instituto de Ciências Humanas e Sociais da Universidade Federal de Mato Grosso (UFMT), campus de Rondonópolis. E-mail: shdmaciel@gmail.com.
}

(C) Revista Moara ISSN 0104-0944 (Impresso), n.37, jan.-jun., Estudos Literários, 2012.

Programa de Pós-Graduação em Letras / Universidade Federal do Pará. Todos os direitos reservados. 
O escritor Jorge Amado, assim como os demais escritores mencionados, publicou em vida duas obras compreendidas como textos de memórias, após ter lançado aproximadamente trinta volumes de prosa de ficção que tiveram enorme sucesso junto ao público que ajudou a formar.

A primeira, intitulada $O$ menino grapiúna, é o relato das memórias de infância de Jorge Amado, escrito em 1980 para uma edição especial da revista Vogue dedicada aos cinquenta anos da carreira do escritor, e publicada pela primeira vez em 1981, em edição não comercializada da MPM Propaganda, que serviu como presente de fim de ano para os clientes.

A segunda, Navegação de cabotagem - apontamentos para um livro de memórias que jamais escreverei, foi publicada em 1992, na comemoração dos 80 anos do escritor e remete à vida adulta de Jorge Amado.

Nota-se que em ambas há um aspecto comemorativo que pode ser relacionado ao caráter autopromocional mencionado como marca da escrita de memórias e que ocorre exemplarmente nas memórias de escritores. Entre os dois textos de memórias, no entanto, existem diferenças que vão além da década que os separa. Vejamos.

\section{$1 O$ menino grapiúna e a aceitação das memórias}

As memórias de infância do escritor estão divididas em dezoito capítulos curtos e enumerados e apresentam para cada início de capítulo uma página em branco com o número em negrito em fonte grande que corresponde ao capítulo que será escrito. A obra apresenta, ainda, na abertura de cada capítulo, ilustrações representativas do conteúdo que será tratado. Inicia-se sempre com letras capitulares que sinalizam a entrada num mundo de aventuras e imaginação de menino.

A atmosfera infantil sugerida, a princípio, pelo título $O$ Menino Grapiúna, pelas ilustrações, pelas letras em formato grande, segundo Lima (2009, p.85), escondem uma importância especial, pois no livro "não encontramos memórias fortuitas de uma infância, mas uma espécie de mito de origem de Jorge Amado como autor", pois; ao construir este mito, "o escritor se coloca ao mesmo tempo como personagem, sendo obrigado a lançar mão de uma estratégia narrativa para descrever a si próprio."

Neste sentido, é importante lembrar que ao lermos uma história de vida, devemos estar sempre conscientes de que o autor nos conta apenas uma parte de sua história, que escolhe os fatos de maneira a nos apresentar certa imagem elaborada de si. Do sujeito gramatical à construção de um eu autobiográfico, o que temos de específico é o trabalho com a linguagem e as escolhas que cada escritor tece para a urdidura de seu enredo pois a imagem elaborada de si é sempre uma construção.

Dentre os personagens que permeiam estas memórias estão prostitutas, vagabundos, mestre de saveiros, capoeiristas, macumbeiros, jagunços, coronéis, feirantes, aventureiros que fazem parte também de sua produção literária. Nas aventuras do menino grapiúna estão presentes, também, as personagens familiares.

A obra é iniciada com a cena em que o pai do escritor fora vítima de uma tocaia, no ano de 1913, na época das lutas travadas pela posse de terras no sul da Bahia, durante o ciclo do cacau. No posfácio, "Memória, 1981", Moacir Scliar diz que de tanto ouvir a mãe contar, a cena se tornou real na lembrança do menino: a égua tombada morta, e o pai, ensanguentado, erguendo o bebê do chão e o levando para casa no colo. Jorge Amado tinha, então, apenas dez meses de idade. "Meu pai cortava cana para égua, sua montaria predileta, postado atrás de uma goiabeira, a repetição apoiada na forquilha de um galho (assim o enxergo na nítida rememoração), [...]" (AMADO, 1982, p. 13). 
Tanto para o personagem menino grapiúna, quanto para o escritor, lembrança e imaginação se interligam. Permeadas pelas principais marcas da obra amadiana, $O$ Menino Grapiúna faz a defesa da liberdade, da imaginação e do sonho mergulhados nas memórias de sua infância. Muito mais que rememorar sua formação de menino, Jorge Amado passa em revista elementos centrais de sua literatura.

Segundo Bosi (1989), a obra de J. Amado se desdobra temporalmente em cinco movimentos específicos: 1. Romance proletário; 2. Romance de rixas e amores marinheiros; 3. Escritos de pregação partidária; 4.Narrativas da região do cacau; 5.Crônicas de costumes provincianos com o apimentado do regional (BOSI, 1989, p.459). Para o crítico, trata-se de uma obra de tensão mínima, que apenas esboça "largos painéis coloridos e facilmente comunicáveis" (BOSI, 1989, p.458), juízo de valor negativo que, no entanto, aponta os temas da região do cacau como os mais felizes em sua obra.

E são os temas da região do cacau que servem como motivação para a memória do narrador em $O$ menino grapiúna. Sem ser unicamente pessoal por ser capaz de transcenderse ao falar da vida e da cultura de sua aldeia, o escritor retoma uma espécie de origem de si e de sua obra calcado ora em "relatos ouvidos" (AMADO, 1982, p.13) ora no que ele acredita ser a "memória verdadeira e completa" (AMADO, 1982, p.23).

Os acontecimentos que se sucedem representam a vida dos indivíduos envolvidos no processo de construção de uma região que demarcará um ciclo que fará parte da memória do menino: o ciclo do cacau. A narrativa acompanha a busca desenfreada do homem pela terra que, neste contexto, significava a aquisição do poder.

Vê-se, como é comum num texto de memórias, que todo um panorama histórico vai sendo desvendado à medida que a personagem central ganha seus contornos. A busca pelo poder, as lutas travadas, o derramamento de sangue e a formação da nação grapiúna são o pano de fundo desta história da qual o menino faz parte.

Em alguns momentos da narrativa, o narrador personagem prossegue o curso no resgate de suas lembranças de menino e ao dizer que "Lavaram o chão de cimento com umas poucas latas de água, recordava minha mãe." (AMADO, 1982, p.18) afirma a ligação de sua narrativa com a narrativa materna. Portanto, essa lembrança continua entrelaçada à narrativa materna que também se tratava de recordações:

\footnotetext{
$\mathrm{Na}$ verdade, todos "refazemos" o passado, e um ato de repetição deve ser entendido, não como um ato que simboliza um acontecimento passado específico, mas como toda uma história de tentativas de resgatar o passado, uma história que é colocada num contexto num dado momento, quando ocorre a repetição. (ROSENFIELD, 1994, p. 84).
}

É a partir das histórias contadas pela mãe que Jorge Amado reelabora suas memórias de infância ou refaz o passado. Ao fazer uma segunda leitura dos fatos vividos o escritor memorialista realiza um profundo diálogo entre passado e presente. Busca ainda significações contidas nos fatos passados e reorganiza-os no presente.

Segundo Braga (2000, p.96), a memória pessoal ou autobiográfica, na infância, é circunscrita à família e a pequenos grupos, porque as crianças compreendem de maneiras particulares os fatos que fazem parte da memória histórica: "Somente mais tarde somos capazes de recolocar nossas lembranças de infância em um quadro histórico.", neste sentido, as primeiras memórias expressas no livro estão relacionadas à narrativa memorialística da mãe do personagem menino grapiúna, que as assimilou e assim, passaram a se constituir como suas. 
Ao revelar a violência e a miséria na luta pela conquista das terras no sul da Bahia, o escritor de memórias passa em revista os enfrentamentos dos desbravadores das futuras roças de cacau. E, nesta parte, atua com participante da sua própria narração. A verbalização ocorre a partir de seu ponto de vista. O verbo na primeira pessoa - "acompanhei" - o conduz como sujeito desta história, sem a participação da mãe.

Ao buscar recompor sua história, as recordações do menino grapiúna também evoluem nos capítulos que seguem. Suas aventuras sexuais, o internato no colégio dos jesuítas e o encontro com os livros que iriam determinar seu futuro de escritor: "Recordo com carinho a figura do jesuíta português erudito e amável. Menos por ter me anunciado escritor, sobretudo por me haver dado amor aos livros, por me haver revelado o mundo da criação literária." (AMADO, 1982, p. 119).

Guardadas na memória, o homem Jorge Amado traz suas lembranças à tona e eventos esparsos são rememorados e reconstituídos. Ao evocar experiências vividas na infância, o escritor atua no processo de reconstrução de si num jogo entre passadopresente, pois, segundo Rosenfield (1994, p.86) "o passado e o presente entrelaçavam-se de algum modo numa recordação mais "real", mais vivida." E, ao ativar a memória na tentativa de resgatar o vivido, algumas partes dessa vivência pode se perder. Quando resgatadas as lembranças passam atuar em outro momento, ou seja, no presente que reelabora os fatos experienciados e os seleciona:

[...] a memória não é uma repetição exata de uma imagem no cérebro, mas uma recategorização. [...] A recategorização de objetos ou acontecimentos depende tanto do movimento quanto da sensação, e constitui uma habilidade adquirida ao longo da experiência. Toda pessoa, segundo a teoria de Edelman, é única: suas percepções, até certo ponto, são criações, e suas lembranças fazem parte de um processo contínuo de imaginação. A vida mental não pode ser reduzida a moléculas. A inteligência humana não consiste apenas em saber, porém em reelaborar, recategorizar e, com isso, generalizar informações de maneira nova e surpreendente. (ROSENFIELD, 1994, p. 2009).

Neste sentido, podemos considerar as memórias contidas em $O$ menino grapiúna como lembranças da vida do escritor, revistas e reconstruídas na sua fase adulta. Memórias que sofreram alterações devido ao tempo, visto que o momento da produção escrita é outro e as influências que irão determinar o que se pode ou deve escrever estão relacionadas ao pensamento seletivo de seu autor, no momento da enunciação.

Cabe ressaltar que essas memórias de infância, permeadas pela materialidade linguística da lembrança e do esquecimento, as duas faces da moeda da memória, são apresentadas pelo autor e pelo editor como memórias de fato, mesmo que, assim como em Navegação de cabotagem, o vocábulo memórias não conste do título.

Aceito como um retorno organizado ao passado, $O$ menino grapiúna é um texto de memórias narrado numa sucessão linear de acontecimentos. É produzido, portanto, dentro de uma tradição de escrita de memórias em que um narrador autodiegético promove um retorno a um passado distante, neste caso a infância, com o intuito de compreender o presente. Em nenhum momento seu autor nega ou questiona a especificidade do gênero memórias ou de seu estatuto. Sob este aspecto, $O$ menino grapiúna, apesar de mais palatável que seu sucessor, é menos singular no tocante à estrutura da narrativa, posto que não subverte ou inova a tradição memorialista e pode ser recebido como a ilustração de uma vida privada de uma personalidade de prestígio, que é sempre interessante e atemporal. 


\title{
2 Navegação de Cabotagem e a negação das memórias
}

Publicado em 1992, Navegação de cabotagem reúne, sem rígida organização cronológica, as lembranças de Jorge Amado. O escritor, que testemunhou grandes acontecimentos do século XX e em sua trajetória pessoal desempenhou papel importante na cultura brasileira, além de conviver com algumas das personalidades mais representativas do Brasil e do mundo, narra, num estilo aparentemente despretensioso, os fatos de seu passado.

Em Navegação de cabotagem - apontamentos para um livro de memórias que jamais escreverei - Jorge Amado deixa recordações de acontecimentos da vida familiar; faz menções calorosas aos amigos pessoais; comenta suas obras e as adaptações televisivas e cinematográficas que elas inspiraram; relembra escritores e artistas com quem conviveu e, ainda, aponta os numerosos portos dessa navegação. Ainda sobre Navegação de cabotagem, Goldstein, 2002, afirma que:

\begin{abstract}
[...] narra peças que pregou e pequenas espertezas que poderiam estar em sua ficção, além de uma quantidade considerável de capítulos tratar de lembranças culinárias. O lado "Don Juan" é lembrado com orgulho: "eu rosetava de leito em leito: mulheres em abundância, tantas, eu quase não dava abasto, sobravam da agenda em grande parte ocupada pela atividade política. Eu apenas descansava das lides políticas no regaço de casadas e solteiras [...]" (Amado, 1992, p.8). Ou seja, o escritor constrói a sua própria imagem como malandro, apreciador da culinária baiana, mulherengo e mestre na arte da amizade - sem contar que antecedentes indígenas são lembrados em diversas entrevistas, legitimando a condição de mestiço. (GOLDSTEIN, 2002, p.117).
\end{abstract}

Sobre Navegação de cabotagem, Aguiar nos diz que poderemos encontrar uma grande quantidade de pessoas com quem o escritor conviveu, pois;

Uma medida dos tantos que ele conheceu, e dos muitos de quem se tornou amigo, tem-se com os 1.211 personagens reais, contados do índice remissivo, que povoam Navegação de cabotagem - apontamentos para um livro de memórias que jamais escreverei - o mais próximo de uma autobiografia a que Amado chegou. (AGUIAR, 2006, p.35).

A proximidade com a autobiografia de que nos fala Aguiar (2006) talvez esteja relacionada à insistente negação de memórias apresentada pelo autor desde o início da obra em discussão. Entretanto, não podemos desconsiderar que os limites entre autobiografia e memórias são tênues. Num sentido amplo, não há distinção entre escrita autobiográfica e escrita memorialista: "Difícil traçar o limite exato entre a autobiografia, as memórias, o diário íntimo e as confissões, visto conterem, cada qual a seu modo, o mesmo extravasamento do "eu"". (MOISÉS, 2002, p.50).

Quando nos remetemos à especificidade da forma narrativa, entretanto, há que considerar a idiossincrasia de autobiografia e de memórias:

A diferença entre a memória e a autobiografia é também tênue e parece estar evidenciada na busca específica para qual este "eu", de vida comprovada (ou não), se remete: se a busca das memórias equivaleria a de um historiador que procura no passado aquilo que explique o presente e o desenrolar de fatos diversos, na autobiografia o relato se daria segundo critérios que sirvam para reforçar a história de uma personalidade, ou seja, da existência deste eu-narrador. Se nas memórias temos um "eu" que quer tirar do passado uma leitura do mundo, 
na autobiografia temos um "eu" que quer tirar do mundo o que seja a sua própria história. (MACIEL, 2004, p.85)

Navegação de cabotagem, neste âmbito, parece usar o vetor eu-mundo, ou seja, é um tipo de narrativa em que o narrador parte de si para desvendar o mundo. Esta navegação eu-mundo fica clara na maior parte dos apontamentos, tal como em:

Presido à sessão dedicada aos intelectuais e à democracia no Fórum Cultura e Democracia, reunido em Praga sob os auspícios da UNESCO e do Presidente Havel, da Tchecoslováquia. Estão escritos para debater o tema dos romancistas André Brink, da África do Sul, Tahar Bem Jelloun, de Marrocos, o húngaro Jorgen Konrad, Presidente do Pen Clube Internacional, o Presidente do Conselho Nacional de Cultura do México, Victor Flores Ojea e Jean-Daniel, diretor de Le Nouvel Observateur. Os problemas se avolumam com a abertura para a vida democrática dos países até ontem satélites do império soviético. (AMADO, 2006, p.262).

Neste trecho, o verbo inicial "Percebo" indica a presença do narrador em primeira pessoa em um tempo e em um espaço precisos, "Praga,1991", informação que antecede o apontamento. Do lugar que este eu ocupa parte-se para, não um aprofundamento de si, como é comum na autobiografia, mas a uma percepção sobre o momento histórico e seus desdobramentos, tal como costuma ocorrer em textos de memórias.

As memórias amadianas são constituídas por pedaços (apontamentos) que se juntam formando um grande mosaico que representa a sua própria vida. Cada apontamento inicia uma nova história formando um conjunto sugestivo de continuidade, ou seja, o desejo de não morrer. Em cada leitor sempre existirá a possibilidade de renascimento e da vida prosseguir. Assim, no conjunto dos apontamentos, Jorge Amado conclui o seu projeto memorialístico no qual se perpetuará. Ao compreender isto, se estabelece a interação entre autor/obra/leitor.

Apesar dessa verificação, Jorge Amado insiste que Navegação de cabotagem não é exatamente um livro de memórias. O livro é composto por apontamentos numa desordem cronológica sem compromisso com precisão de datas. Numa espécie de prefácio ou apresentação do livro o autor diz que "de logo quero avisar que não assumo qualquer responsabilidade pela precisão de datas, sempre fui ruim para datas, elas me perseguem desde os tempos de colégio interno." (AMADO, 2001, p.2).

O percurso desta navegação é pelas correntezas da memória, pois "À proporção que me vinham à memória, começaram a ser postas no papel a partir de janeiro de 1986" (AMADO, 2001, p.1). Amado diz que "A referência a ano e a local destina-se apenas para situar no tempo e no espaço o acontecido, a recordação. " (AMADO, 2001, p.4). Ao desvincular-se do compromisso de ser preciso com os acontecimentos em relação a datas e espaço, acontecimentos passados são retomados a partir de suas lembranças no presente, num processo descontínuo, pois;

Não existem recordações específicas em nosso cérebro; existem apenas meios de reorganizar as impressões passadas, de dar ao mundo incoerente e onírico da memória uma realidade concreta. As memórias não são fixas, mas sim generalizações - recriações - do passado que estão em constante evolução, dando-nos um sentimento de continuidade, um sentimento de existência, com passado e futuro. Elas não são unidades distintas, vinculadas ao longo do tempo, e sim um sistema em evolução dinâmica. (ROSENFIELD, 1994, p. 80-81). 
Escrito, segundo Jorge Amado, à proporção que lhe vinham à memória, sem nenhum compromisso com datas e locais Navegação de cabotagem, apesar da negação de seu autor e personagem, assume as características de um livro de memórias. Aparentemente desorganizado e redigido em forma de apontamentos, o livro revive as aventuras de uma personalidade ora com certezas ora cheia de imprecisões.

Para Halbwachs (2006) nossas lembranças emergem do contato com os outros ou originam-se de situações sociais, assim, a memória está relacionada a um grupo social real ou imaginário - em uma comunidade afetiva de forma que, quando nos lembramos, deslocamo-nos de um grupo a outro, em pensamento. Neste sentido, a memória depende da linguagem e dos significados constituídos socialmente.

A rememoração é uma reconstrução ou uma construção imaginária, que nasce da relação, segundo Rosenfield (1994, p. 209), da "nossa atitude perante toda uma massa ativa de reações ou experiências organizadas do passado e um pequeno detalhe destacado, que comumente aparece sob a forma de linguagem". No prefácio de Navegação de Cabotagem, Jorge Amado reconhece que suas lembranças transcendem para a linguagem, pois, juntamente com acontecimentos e pessoas, assume, nas páginas, uma nova configuração por meio do ato de contar.

Para Jorge Amado o "contar" ocorre na escrita, porque escrever é um modo de ser e estar na vida. De acordo com Olmi (2006, p. 23-24), narrar é preciso para que "nossa vida sempre exista dentro de uma narrativa que dirigimos a nós mesmos ou a outros". As palavras de Amado revelam este desejo de apenas querer contar algumas coisas, mas também expressa o desejo de permanecer, assim;

Consciente e contente que assim seja, reúno nesta Navegação de Cabotagem lembranças de alguém que teve o privilégio de assistir, e por vezes de participar de acontecimentos em certa medida consideráveis, de ter conhecido e por vezes privado com figuras determinantes. [...] Quero apenas contar algumas coisas, umas divertidas, outras melancólicas, iguais à vida. (AMADO, 2001, p.4).

Deste modo, o escritor afirma que Navegação de cabotagem não é um livro de memórias, negadas já no subtítulo da obra, pois apenas quer contar algumas coisas iguais à vida, mas nesse contar está claro que existe implícita uma autopromoção ao afirmar que participou de "acontecimentos consideráveis". A negação de suas memórias pode ser compreendida como uma estratégia do escritor para despertar o interesse do leitor e, ao mesmo tempo, se firmar no futuro. A tentativa de resgatar o passado e trazê-lo para o presente é, na verdade, uma forma de perpetuar-se.

A negação de suas memórias, além de já existir no subtítulo, aparece também no enunciado "um quase livro de memórias", parece remeter, pelo contrário, à afirmação de suas memórias. Aliás, o termo "quase-memória" aparece, duas décadas antes, na introdução de Solo de Clarineta (1974) para explicar as memórias de Érico Veríssimo. Também aparece, cerca de três anos depois, na obra Quase memória: quase-romance (1995), de Carlos Heitor Cony. De qualquer forma, todas as memórias, sob o contexto da recuperação do passado, são escritas sob o signo do quase.

Trazer à tona acontecimentos passados exige reorganizar a própria vida na ordem cronológica dos fatos, mas o tempo modifica nossas percepções das coisas e dos outros e faz também nossas recordações dos acontecimentos variarem porque olhamos para o passado de outro ponto de vista: "O tempo não é uma qualidade absoluta da memória; ele é uma ordenação das pessoas, lugares, coisas e acontecimentos. Não existem calendários no cérebro." (ROSENFIELD, 1994, p. 176). 
Por isso, datas e sequências de acontecimentos se misturam na memória, pois passado e presente se entrelaçam produzindo uma nova narrativa dos momentos vividos.

Ao narrarmos uma existência, diz Forest, a transformamos em romance, penetrando, assim, na fábula. Pensamos estar narrando ou dizendo a verdade a respeito da nossa própria vida, mas, logo que refletimos sobre o fato, nos damos conta de que toda narrativa, mesmo a mais íntima, assumiu a forma "obrigatória" da ficção. (OLMI, 2006, p.109).

Realidade e ficção se misturam e seria impossível separá-las porque a divisa entre verdade e imaginação é imperceptível na arte da escrita literária. Como o próprio Jorge Amado afirma: "Ao escrever um romance realizo um trabalho artesanal, sou um artesão tentando alcançar a arte literária. Quando inicio um livro somos apenas eu, a máquina de escrever, o papel em branco." (AMADO,2001, p.256). Neste "eu" que escreve Navegação de cabotagem reside também o "eu artesão" que busca revelar-se através da arte no ato de reviver seu passado e reconstruí-lo para perdurar-se no futuro. Reviver o passado é a oportunidade que o escritor tem de refazê-lo, agora, da maneira que melhor lhe pareça.

Ao reviver acontecimentos passados é comum sentir-se inseguro porque reviver o passado é remexer em coisas que estão acomodadas e distantes, assim,

\begin{abstract}
É como se tomássemos uma estrada que percorremos outrora, mas de viés, como se examinássemos de um ponto de onde jamais havíamos visto. Temos de recolocar os diversos detalhes em outro conjunto, constituído por nossas representações do presente. Parece que chegamos a uma nova estrada. Os detalhes só retomam seu antigo sentido em relação a todo um conjunto novo que nosso pensamento já não abrange. Poderíamos nos lembrar de todos os detalhes em sua respectiva ordem. É do conjunto que temos de partir - mas isto não possível, porque há muito tempo nos afastamos dele e teríamos de votar muito tempo atrás. (HALBWACHS, 2006, p. 37).
\end{abstract}

Valendo-se da linguagem e estabelecendo um importante elo entre consciência, conhecimento, autoconsciência e temporalidade, o escritor baiano permanece numa viagem contínua que pode iniciar aleatoriamente em qualquer página de Navegação de Cabotagem, visto que qualquer um dos apontamentos serve como um porto para o embarque.

Segundo Olmi (2006, p.110), "quanto à narrativa de uma vida, todos têm direito de realizá-la, e retomar posse dessa narrativa se torna para aquele protagonista, um gesto autêntico de libertação, de verdade e de cognição". Por isso não importa se as memórias contidas em Navegação de Cabotagem são negadas ou expressas, pois "[...] a autobiografia conduz necessariamente à autofiction, porque há sempre uma invenção do eu. [...]." (OLMI, 2006, p.110). Esta invenção, é importante ressaltar, aparece carregada de informações monumentais em que o "eu" vive algo fora de medida, porque está próximo de quem faz a História ou porque faz parte de acontecimentos relevantes para a época.

\title{
3 Porto de chegada: opostas ou complementares?
}

A princípio, O menino grapiúna e Navegação de cabotagem deixam transparecer a ideia de oposição. As obras estão colocadas em momentos diferentes e uma revelação antagônica se estabelece neste sentido, visto que a primeira trata do período que vai da infância até a adolescência e a segunda refere-se à fase adulta da vida do escritor. 
A sugestiva oposição entre as obras de memórias de Jorge Amado, estabelecida por períodos de vida diferentes, no entanto, logo é desfeita por meio de uma leitura mais atenta posto que é perceptível uma sequencialidade ou até mesmo uma interligação: fatos já rememorados em $O$ menino grapiúna são retomados em Navegação de cabotagem. Temos como exemplo, o tio Álvaro, o tio predileto do menino grapiúna que foi;

Um dos homens mais agradáveis que conheci, incompatível com a tristeza, [...] Ganhando dinheiro facilmente, mais facilmente ainda o gastava,[...] Um dos hábitos consistia em comparecer a reuniões e festas, na longa estação das chuvas, um guarda-chuva velho que depositava junto aos demais,[...] (AMADO, 1982, p. 72-73).

O tio admirado pelo menino está presente nas memórias da fase adulta de Jorge Amado e a admiração e fascínio pela personagem da sua infância são novamente rememorados: Meu tio Álvaro tinha hábitos que me deslumbravam, o dos guarda-chuvas
referido por meu pai era um deles, eu o via sair com o guarda-chuva velho,
esperava vê-lo de volta, o riso no canto da boca, o guarda-chuva novo pendurado
no braço. Dia chuvoso a prática repetia-se: tio Álvaro partia levando o objeto
imprestável, onde chagasse - bar, restaurante, casa de amigos, casa de putas -
colocava-o no porta-chapéus, ao retirar-se ali o deixava, escolhia em troca o de
melhor qualidade e menos uso. Terei saído a ele, como temia meu pai, o coronel
João Amado? Meu tio Álvaro Amado, tão grande figura, o mais fascinante
personagem de minha infância, nunca ousei colocá-lo herói principal de um
romance. Quando aparece é sempre em segundo plano: não se mostrava, agia na
discrição. Amava as coisas velhas, terno seu durava uma eternidade, saí a ele.
(AMADO, 2001, p.520).

O mesmo relato do caso dos guarda-chuvas e da esperteza do tio Álvaro é rememorado nas páginas de Navegação de cabotagem pelo escritor e personagem Jorge Amado. Entre o menino e o homem adulto a ligação se estabelece pelos fatos revividos. Aquilo que tinha valor para o menino parece continuar na memória do homem Jorge Amado com igual valor. Para o menino, tio Álvaro era uma: "Personalidade sedutora, teveme sempre sob a sua proteção, dava-me categoria de amigo, por vezes de cúmplice." (AMADO, 1982, p.72).

Para o homem Jorge Amado "[...] meu tio Álvaro Amado, irmão caçula do pai de Jorge Amado. [...] pobre e perdulário, jogador de pôquer batoteiro, herói a imitar." (AMADO, 2001, p.520). Assim, mesmo reconhecendo que seu personagem era possuidor de algumas qualidades que não lhe atribuíam valores heróicos, Jorge Amado o considera como um "herói a imitar". Deste modo menino e homem têm, por esse personagem rememorado, admiração. Tio Álvaro permanece como amigo e cúmplice nas memórias do escritor.

Recordações que remetem à infância do escritor são frequentemente retomadas em Navegação de cabotagem. O sabor da infância grapiúna transcende o tempo e permanece na memória de Jorge Amado, aproximando as duas narrativas separadas pelo tempo. Além disso, em $O$ menino grapiúna e em Navegação de Cabotagem o narrador personagem muito mais que rememorar a sua história, "mostra o início de uma trajetória literária que marcou o nosso país." (SCLIAR, 2010, p.68).

Apesar de vários assuntos serem análogos nas duas obras, é na segunda, Navegação de cabotagem, que a ideia de autopromoção mais se configura porque é na fase adulta que o homem Jorge Amado assume as tarefas que lhe darão relevância como ser humano 
dentro do que socialmente é aceito como importante ou célebre. Ambos são livros de memórias, mas a marca da exemplaridade se fortalece nos apontamentos selecionados como relevantes pelo autor que, aos oitenta anos, tem muita coisa para contar. Os apontamentos são um "disfarce" - critério adotado pelo escritor para esconder o tom de memória ou mesmo de confissão do livro. Por disfarce compreende-se o cerne da ficção, ou da autoficção, como vimos.

Na relação entre subjetividade e criação literária, o escritor vai desenhando a vida nas páginas dos seus livros de memórias. Como um grande painel revelador, $O$ menino grapiúna e Navegação de cabotagem mostram muito mais que os componentes desta história particular; mostram que a correnteza da memória pode ser vivida de diferentes formas e não se esgota essencialmente em uma única experiência literária.

\section{REFERÊNCIAS}

AGUIAR, J. As Cartas De Uma vida Inteira. Entre Livros. São Paulo, v.2, n¹6. São Paulo: Duetto, 2006.

AMADO, J. Navegação de cabotagem: apontamentos para um livro de memórias que jamais escreverei. 5. ed. Rio de Janeiro: Record, 2001.

AMADO, J. O menino grapiúna. Rio de Janeiro: Record, 1982.

BOSI, A. História concisa da literatura brasileira. São Paulo: Cultrix, 1989.

BRAGA, E. S. O trabalho com a literatura: memórias e histórias. Cadernos Cedes, Campinas,SP, v.20, n50, abr.2000.

CONY, C. H. Quase Memória: quase-romance. 7.ed. São Paulo: Companhia das Letras, 1995.

HALBWACHS, M. A Memória Coletiva. Tradução de Beatriz Sidou. São Paulo: Centauro, 2006.

LIMA, M. R. P. A Face Mestiça da verdade: memória, subjetividade e experiência de um escritor do século XX. UFRJ: Rio de Janeiro, 2009.

MACIEL, S. D. A literatura e os gêneros confessionais. In: BELON, A. R.; MACIEL, S. D. Em diálogo: estudos literários e lingüísticos. Campo Grande: Editora da UFMS, 2004.

MOISÉS, M. Dicionário de Termos Literários. São Paulo: Cultrix, 2009.

OLMI, A. Memória e memórias: dimensões e perspectivas da literatura memorialística. Santa Cruz do Sul: EDUNISC, 2006.

ROSENFIELD, I. A invenção da Memória: uma nova visão do cérebro. Rio de Janeiro: Nova Fronteira, 1994.

SCLIAR, M. Retrato do artista quando jovem [posfácio]. In: AMADO, J. O menino grapiúna. São Paulo: Companhia das Letras, 2010.

VERÍSSIMO, E. Solo de Clarineta: memórias. Porto Alegre: Globo, 1974. 